\title{
Reactivity Indices related to DFT Theory, the Electron Localization Function (ELF) and Non-Covalent Interactions (NCI) Calculations in the Formation of the non-Halogenated Pyruvic Esters in Solution
}

\author{
Souad. Jorio ${ }^{1, *}$, Mohammed. Salah ${ }^{1}$, Hassna. Abou El Makarim ${ }^{2}$ and Mohammed Tabyaoui $^{3}$ \\ ${ }^{1}$ Molecular Modeling and Spectroscopy Team MMST, Laboratory of water and environment, Chouaïb Doukkali \\ University, Faculty of Science, Department of Chemistry, El Jadida Morocco \\ ${ }^{2}$ Laboratory of Spectroscopy, Molecular Modeling, Materials, Water and Environments: LS3MN2E-CERN2D, \\ Mohammed V University, Faculty of Sciences, Department of Chemistry, Rabat, Morocco \\ ${ }^{3}$ Laboratory of Materials Nanoparticles and Environment, Mohammed V University, Faculty of Sciences, \\ Department of Chemistry, Rabat, Morocco
}

\begin{abstract}
The non-halogenated pyruvic esters are essential compounds, considering that they exhibit particular properties, due to the proximity of two functional groups: carbonyl and ester. These molecules can be obtained from the approach of the Lewis acid $\mathrm{MgI}_{2}$ on the iodinated pyruvic ester by using sodium hydrogen sulfite in aqueous solution, which selectively reduces the carbon-iodine bond of the iodinated pyruvic ester. The sites of attack of hydrogen sulfite of this reaction remained uncertain and were the subject of a debate between the experimenters. Our aim in this work is to determine the more favorable sites of attack by using the local indices (Parr functions). To approve the structure of the reagents, we have conducted a topological analysis of electron localization function (ELF). To reveal the type of interaction in the "ester pyruvic-hydrogen sulfite" complex, we have performed a non-covalent interactions (NCI) calculation. The analysis of local indices and NCI analysis of electron density indicate that the approach of the hydrogen sulfite ion will take place on the iodine atom elucidating the preferable site of the attack.
\end{abstract}

Keywords: non-halogenated pyruvic ester, carbon iodine bond, DFT theory, ELF, NCI.

\section{Introduction}

The non-halogenated pyruvic esters are chemical compounds of formula R-CO-COOR'. They have both a carbonyl and an ester functional group. These molecules and their derivatives frequently exhibit particular properties due to the proximity of these two functional groups, whose reactivity is modified and often exalted ${ }^{1-4}$.

This singular behavior of these molecules and their derivatives has attracted considerable interest as<smiles>[R3]OC(=O)C(=O)C([R12])([R4])I</smiles>

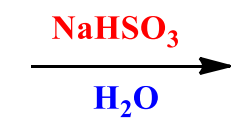

Scheme 1. Reaction of the iodinated pyruvic ester with sodium hydrogen sulfite in aqueous solution.

Our previous work on glycidic series ${ }^{9}$ showed that the iodinated pyruvic ester is formed from the approach of Lewis acids $\mathrm{MgI}_{2}$ to the $\alpha$-chloroglycidic intermediates in many biological processes ${ }^{5-7}$. The non-halogenated pyruvic esters can be obtained experimentally in aqueous solution from the approach of the Lewis acid $\mathrm{MgI}_{2}$ on the iodinated pyruvic ester ${ }^{8}$ using sodium hydrogen sulfite, which selectively reduces the carbon-iodine bond of an iodinated pyruvic ester of the aliphatic series; and thus, leads to the formation of the non-halogenated ester (Scheme 1). ester (Figure.1S, P.484). The optimum distance found for Mg-I is equal to $2.65 \AA$, and the optimized 
structure parameters of the $\alpha$-chloroglycidic ester are listed in the supplement (Table 1S, p. 484).

The sites of attack in this reaction remained uncertain and were the subject of debate among the experimenters ${ }^{8}$. According to them, it is possible to propose two hypotheses comparable to the reaction of Perkow ${ }^{10-12}$, concerning the conversion of an $\alpha$ halogenated ketone to enol phosphate by a trialkyl phosphite. The first hypothesis proposes that the sodium hydrogen sulfite would be added to the most $\alpha$-reactive carbonyl of the ester to give a bisulfite combination which would then evolve through an intermolecular rearrangement to an enol sulfate. The latter would then be hydrolyzed, releasing the enol form of the $\alpha$-ketoester (Scheme 2).
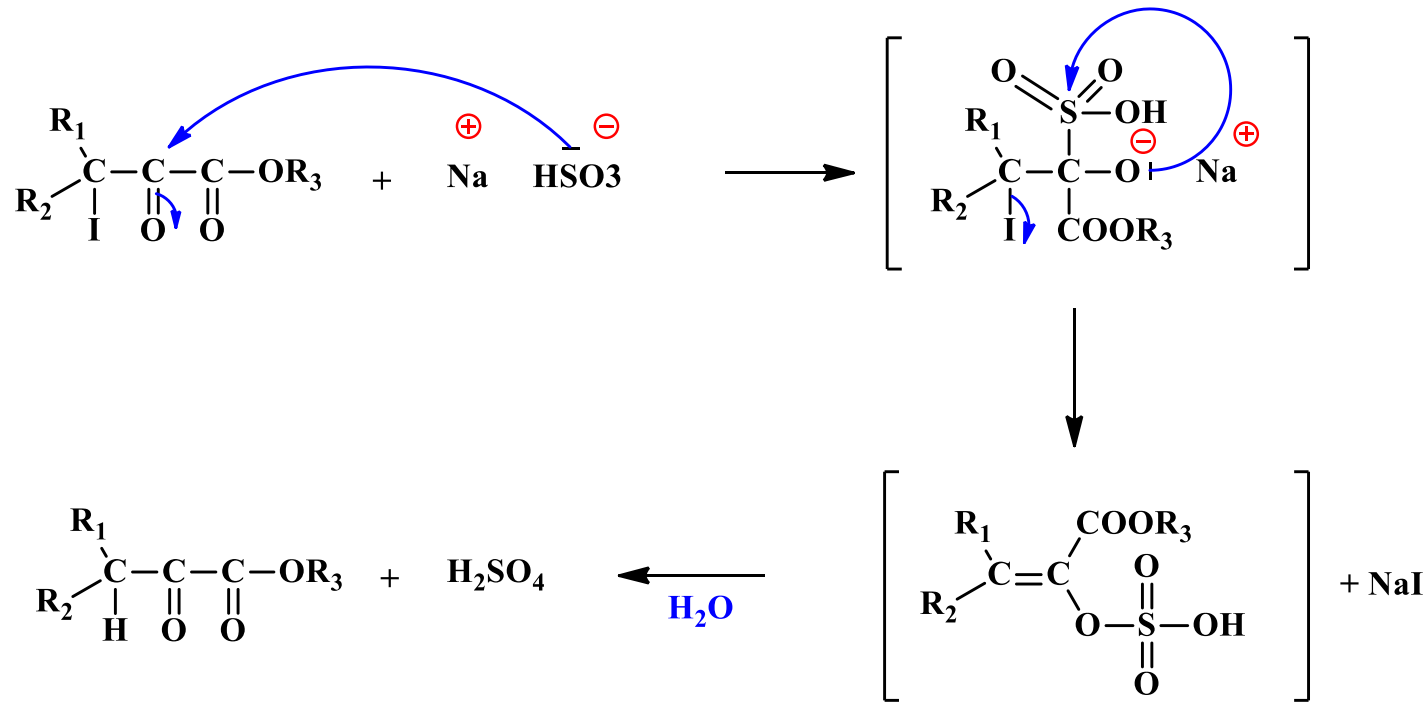

Scheme 2. Formation of the non-halogenated pyruvic product from the attack of the sodium bisulfite on the carbonyl.

The second hypothesis proposes an attack by the

sodium bisulfite at the positively charged iodine (Scheme 3).

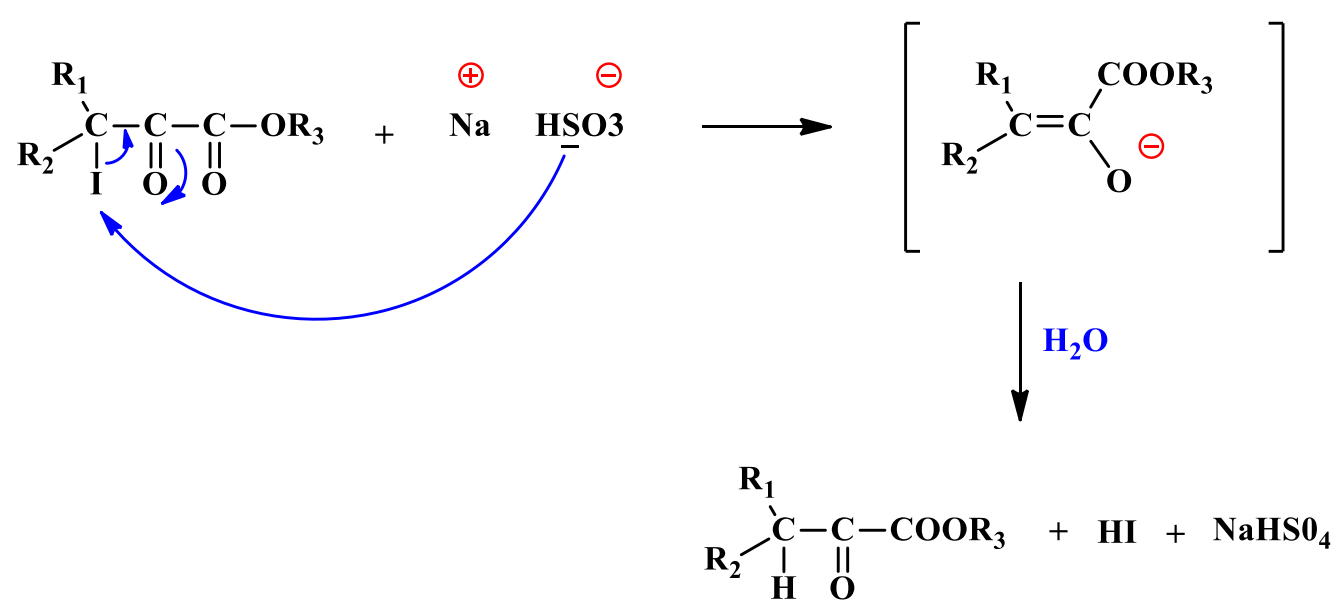

Scheme3. Formation of the non-halogenated pyruvic product from the attack of the sodium bisulfite on the iodine atom.

To understand the reactivity and to illustrate the formation process of the non-halogenated pyruvic product in the glycidic series, we have performed an analysis of the electronic structures of both reactants in terms of the electron localization functions (ELF) 13,14 analysis. In this method, the covalent bonds are intuitively represented using conventional Lewis structures ${ }^{15}$ and can be visualized from properties of the electron density with modern quantum mechanical models of boundary ${ }^{13,14}$. Also, we have applied the non-covalent interactions (NCIs) analysis, which is crucial for describing the interplay of structure and reactivity ${ }^{16}$ for our molecular systems. These non-covalent interactions are based on promolecular density ${ }^{17,18}$ computed from the sum of atomic contributions ${ }^{16}$, which gives similar results as DFT densities ${ }^{19-21}$. This analysis has allowed us to characterize the weak interaction in the approach 
of two fragments and permitted us to unveil the most appropriate approach between the hydrogen sulfite ion and the iodinated pyruvic ester. Finally, we have used the conceptual DFT ${ }^{22-25}$ theory, which has proven its usefulness in the literature as a tool ${ }^{26}$ to predict and explain the chemical reactivity of molecules.

\section{Theoretical background}

Density functional theory ${ }^{19-21}$ (DFT) was used to carry out all chemical quantum computations within Gaussian $09^{27}$ and his interface graphic Gauss View $05^{28}$. Geometry optimization of reactants was performed using B3LYP functional ${ }^{29}$ combined with 6-31G(d) basis sets ${ }^{30-33}$ for $\mathrm{C}, \mathrm{H}, \mathrm{O}$, and S. For the iodine atom we have used the basis set of Dolg ${ }^{34,35}$ which gives more pertinent results than the Huzinaga basis set ${ }^{36,37}$. The core electrons for the iodine atom have been modeled by a pseudopotential ${ }^{38}$. The optimized structural parameters were used in the vibrational frequency calculations in order to verify that minima do not have any imaginary frequency ${ }^{39}$. Solvents effects were considered by using the Tomasi's polarized continuum model ${ }^{40-42}$ (PCM) The electron localization function (ELF) topological analysis 13,14 was performed with the program Multiwfn 43 using the corresponding monodeterminant wave functions of the selected structures. The ELF function is expressed as follows: $E L F=1 /\left(1+\left[D(r) / D_{0}(r)\right]^{2}\right)$; where $D(r)$ indicates the excess of kinetic energy density caused by Pauli repulsion ${ }^{13,14}$ and $\mathrm{D}_{0}(\mathrm{r})$ is the exact kinetic energy density of the non-interacting uniform electron gas 13,14 introduced into the ELF function as a reference. A large ELF value means that the electrons are strongly localized, indicating that there is a covalent bond, a lone pair or an inner shell of the atom involved. The non-covalent interactions (NCIs) based on promolecular density 17,18 were computed by evaluating the electronic density and its derivatives 44,45 . This method enables the identification and visualization of regions of weak interactions 44,45 by providing chemically intuitive isosurfaces of the reduced density gradient expressed as following: $S=1 / 2 \sqrt[3]{3 \pi^{2}}\left[\nabla \rho(r) / \rho(r)^{4 / 3}\right]$. Here, $\rho(\mathrm{r})$ represents the electron density and $\left|\nabla_{\rho}(r)\right|$ stands for the norm of the electron density gradient vector initially introduced in DFT developments.
The visualization of the non-covalent interactions (NCI) was performed using the VMD program ${ }^{46}$. The global electrophilicity $\omega$ is given by $\omega=\left(\mu^{2} / 2 \eta\right)$ in terms of the electronic chemical potential $\mu$ and the chemical hardness $\eta$ which may be approximated by the one-electron energy of the HOMO and LUMO molecular orbitals, $\varepsilon_{\mathrm{H}}$ and $\varepsilon_{\mathrm{L}}$, as $\mu=\left(\varepsilon_{\mathrm{H}}+\varepsilon_{\mathrm{L}}\right) / 2$ and $\eta=\left(\varepsilon_{\mathrm{L}}-\varepsilon_{\mathrm{H}}\right)$ respectively. The values of the global indices are defined in the context of the conceptual DFT ${ }^{22-25}$ The global nucleophilicity index, N, based on the HOMO energies is specified as $\mathrm{N}=$ $\mathrm{E}_{\text {номо }}(\mathrm{Nu})-\mathrm{E}_{\text {Hомо }}(\mathrm{TCE}){ }^{47}$ where tetracyanoethylene (TCE) is taken as reference, because it presents the lowest HOMO energy and has a very large electrophilicity 47,48 . Besides the global electrophilicity and the global nucleophilicity, it is possible to define their local counterparts condensed to a single atom: the local electrophilicity $\omega_{\mathrm{k}}$ and the local nucleophilicity $\mathrm{N}_{\mathrm{k}}$ are easily obtained by using Parr functions $\mathrm{P}(\mathrm{r}) \quad 49$ in which the nucleophilic $\mathrm{P}^{-}(r)=\rho_{s}^{r c}(r)$ and electrophilic $\mathrm{P}^{+}(\mathrm{r})=\rho_{s}^{r c}(r)$ indices ${ }^{49}$ are mostly considered as useful tools for the evaluation of local regioselectivity in polar processes 23-25. Where $\rho_{s}^{r c}(r)$ and $\rho_{s}^{r c}(r)$ are obtained through the analysis of the Mulliken atomic spin density (ASD) of the corresponding radical cation and the radical anion by single-point energy calculations over the optimized neutral geometries by using natural population analysis 23-25 (NPA). The local electrophilicity and local nucleophilicity indices can be redefined according to the expression $\omega_{\mathrm{k}}=\omega \mathrm{P}_{\mathrm{k}}^{+}$ and $\mathrm{N}_{\mathrm{k}}=\mathrm{NP}_{\mathrm{k}}^{-}$.

\section{Results and Discussions}

\section{Analysis of the electronic structure}

The topological analysis of the electron localization function provides a partition of the molecular space in to basin of attractors which have a precise signification functions ${ }^{13,50}$ In our study; the ELF valence basin attractor was calculated at the ground state using B3LYP/6-31G(d) monodeterminant wave functions ${ }^{13,50}$ of the optimized structure of the hydrogeno-sulfite ion and the iodinated pyruvic ester. The representation of the ELF attractor position and the valence basin population are given in Figure 1.

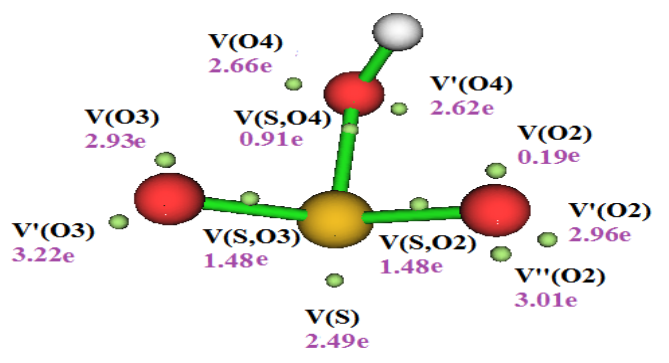

Figure 1. Illustration of the ELF valence attractors positions with corresponding populations in e. 
The application of the ELF topology analysis shows that the presence of a monosynaptic basin $\mathrm{V}(\mathrm{S})$ over the sulfur atom integrates $2.49 \mathrm{e}$. This indicates that there is no bonding region around the sulfur atom. It is equivalent to one lone electron-pair. Equally, Figure 1 shows that the oxygen atoms $\mathrm{O}_{2}$, $\mathrm{O}_{3}$ and $\mathrm{O}_{4}$ present two monosynaptic basins noted $\mathrm{V}$ and $\mathrm{V}^{\prime}$ with total electronic populations equal to $6.16 \mathrm{e}, 6.15 \mathrm{e}$ and $5.28 \mathrm{e}$. These values can be attributed to two lone pair-electrons over the atoms $\mathrm{O}_{3}$ and $\mathrm{O}_{4}$. The value found for $\mathrm{O}_{2}$ can be explained by the presence of three electrons pairs. Consequently, it has a negative charge relative to the oxygen ion according to the Lewis structure.

The bond electrons are assigned to the relevant disynaptic basins; indeed the disynaptic basins $\mathrm{V}\left(\mathrm{S}, \mathrm{O}_{2}\right) ; \mathrm{V}\left(\mathrm{S}, \mathrm{O}_{3}\right)$ and $\mathrm{V}\left(\mathrm{S}, \mathrm{O}_{4}\right)$ which are associated to the bonds $\mathrm{S}-\mathrm{O}_{2} ; \mathrm{S}-\mathrm{O}_{3}$ and $\mathrm{S}-\mathrm{O}_{4}$ are integrating a population of $1.46 \mathrm{e} ; 1.48 \mathrm{e}$ and $0.91 \mathrm{e}$, respectively. This displays delocalized bonds for $\mathrm{S}-\mathrm{O}_{2}$ and $\mathrm{S}-\mathrm{O}_{3}$. We note that the basin of the $\mathrm{S}_{-} \mathrm{O}_{4}$ bond is less populated than the others showing a charge depletion caused by the strong delocalization of the density between the lone pairs of the oxygen atom $\mathrm{O}_{4}$ which exceeds $4 \mathrm{e}$.

For the iodinated pyruvic ester, we noted that the oxygen atom presents two monosynaptic basins (Figure 2) which reveals the presence of two lone electron pairs. Likewise, C-C bonds and C-I bond are characterized by the presence of one disynaptic basin $\mathrm{V}(\mathrm{C}, \mathrm{C})$ and $\mathrm{V}(\mathrm{C}, \mathrm{I})$. The electron populations are somewhat greater than $2 \mathrm{e}$, revealing the covalent aspect of the bonds and indicating the presence of a single bond.

For the ester function, the population values obtained in the disynaptic basin $\mathrm{V}(\mathrm{C}, \mathrm{O})$ are equal to $1.32 \mathrm{e}$ and $1.72 \mathrm{e}$, respectively, indicating an electron delocalization in the bond C-O. Also, the ketonic function has a double bond character because the population of the corresponding disynaptic basin slightly exceeds $4 \mathrm{e}$.

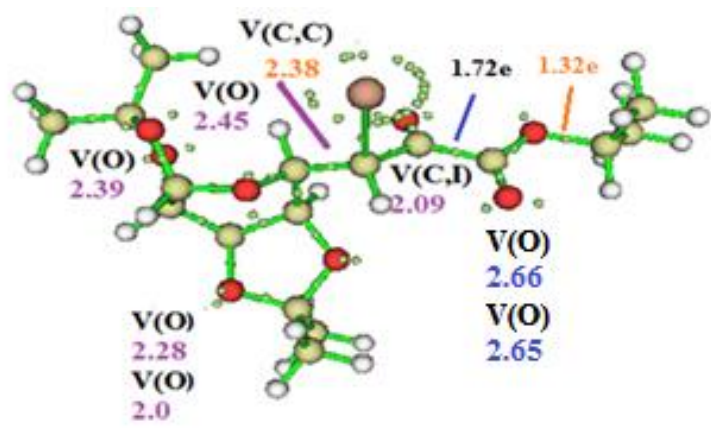

Figure 2. Illustration of ELF valence attractors positions with corresponding populations in e.

We confirm that the topological analysis of the electron localization function is a powerful tool to provide insight into the bonding of molecules and to allow an excellent characterization of the chemical bindings.

\section{NCI analysis of the electron density}

To characterize and to identify the favorable interactions in the approach of the hydrogen sulfite ion and the iodinated pyruvic ester, an NCI of the electron density was performed ${ }^{16,45}$ according to the

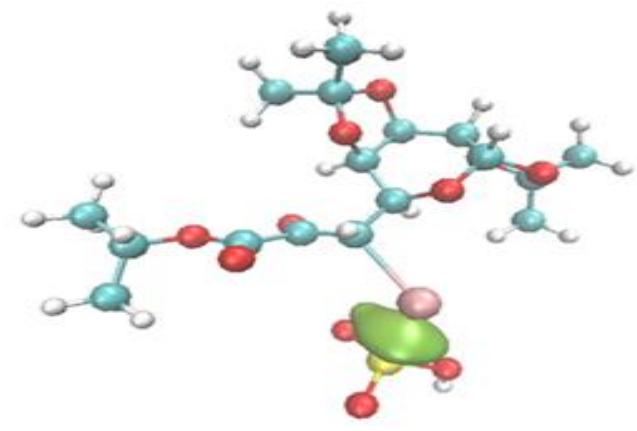

(a) hypothesis given in experiment ${ }^{8}$. This approach provides a rapid and costly representation of van der Walls interactions, hydrogen bonds and steric clashes, requiring only the atomic coordinates as input ${ }^{45}$ These are visualized by the nature of the isosurface formed in the approach of two fragments using the colors green, blue and red, respectively ${ }^{45}$. The NCI low-gradient isosurfaces for different interactions between the two fragments, which are the most plausible in experiment ${ }^{8}$ are displayed in Figure 3.

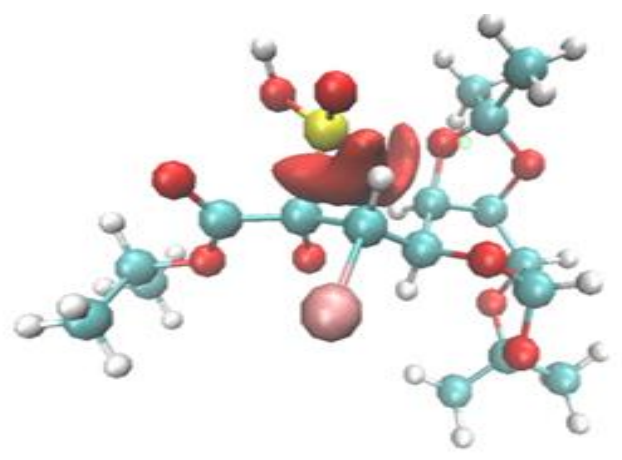

(b)

Figure 3. NCI gradient isosurface formed in the approach of hydrogen sulfite ion to the iodinated atom (a) and in the approach to a carbon atom (b). 
The most significant difference is appearing in Figure $3 \mathrm{a}$ is the presence of a green surface in the approach of the hydrogen sulfite ion to the iodine atom. This sizeable green surface, associated with a weak attractive Van der Waals interaction between the sulfur and iodine atoms ${ }^{45}$ which explains the stabilization of the compound (a). Figure $3 \mathrm{~b}$ shows the approach of the hydrogen sulfite ion to the carbon $\mathrm{C}_{2}$; we note a red surface indicating a repulsive interaction ${ }^{45}$ between the glycidic group and the hydrogen sulfite ion. Consequently, the NCI topological analysis allows us to conclude that the attack of the hydrogen sulfite ion takes place on the iodine atom.

\section{Analysis of the conceptual DFT reactivity Global indices}

To demonstrate the electrophilic or nucleophilic character of the two interacting reagents, namely the hydrogen sulfite ion and the iodinated pyruvic ester (visualized in Figure 1 and Figure 4, respectively). The geometrical parameters are listed in the supplement (Table $2 \mathrm{~S}$ and Table $3 \mathrm{~S}, \mathrm{p} .485$ ), We have calculated the values of the electronic chemical potentials $(\mu)$, the electrophilic indices $(\omega)$, the hardness $(\eta)$ and the nucleophilic indices $(N)$ for the two species, the results are shown in Table 1.

These indices were calculated referring to energies of frontier molecular orbitals ${ }^{49}$. In this context, we have analyzed the atomic coefficients associated with the molecular orbitals ${ }^{51,52}$ ( Table $2 \mathrm{a}$ and Table 2b)<smiles>CC(C)OC(=O)C(=O)[13C](I)(I)[C@@H]1O[C@@H]2OC(C)(C)O[C@@H]2[C@H]2OC(C)(C)O[C@@H]21</smiles>

Figure 4. Optimized structure of the iodinated pyruvic ester.

Table 1. Values of the reactivity indices of hydrogen sulfite $\left(\mathrm{HSO}_{3}^{-}\right)$and iodinated pyruvic ester in eV unity.

\begin{tabular}{cllllll}
\hline Reactants & $\boldsymbol{\mu}$ & $\boldsymbol{\eta}$ & $\boldsymbol{\omega}$ & $\mathbf{N}$ & $\mathbf{S}$ & $\boldsymbol{\Delta} \mathbf{N}_{\max }$ \\
\hline $\mathbf{H S O}_{\mathbf{3}}^{-}$ & -0.98 & 8.90 & 0.05 & 3.31 & 0.11 & 0.11 \\
Iodinated pyruvic & -4.20 & 5.78 & 1.52 & 1.65 & 0.17 & 0.72 \\
\hline
\end{tabular}

$\mathrm{E}_{\text {Hомо }}(\mathrm{TCE})=-8.74 \mathrm{eV}$ calculated at the same level [B3LYP/ 6-31G(d)].

Table 2a. Atomic coefficients $(\times 100)$ of molecular orbitals of hydrogen sulfite ion.

\begin{tabular}{|c|c|c|}
\hline $\mathbf{S}$ & $\left(\mathrm{C}_{\mathrm{s}}\right)_{\text {номо }}$ & $\left(\mathrm{C}_{\mathrm{s}}\right)_{\text {номо-1 }}$ \\
\hline & 49.00 & 3.70 \\
\hline & $\left(\mathrm{C}_{\mathrm{s}}\right)_{\text {LUMo }}$ & $\left(\mathrm{C}_{\mathrm{s}}\right)_{\text {LUMO+1 }}$ \\
\hline & 15.00 & 33.00 \\
\hline \multirow[t]{4}{*}{$\mathbf{O}_{2}$} & $(\mathrm{Co2})_{\text {номо }}$ & $\left(\mathrm{Co2}_{2}\right)_{\text {номо-1 }}$ \\
\hline & 35 & 12 \\
\hline & (Co2)Lumo & $(\mathrm{Co} 2)_{L U M O+1}$ \\
\hline & 13.00 & 19.00 \\
\hline \multirow[t]{4}{*}{$\mathbf{O}_{3}$} & $\left(\mathrm{Coz}_{\text {номо }}\right.$ & $(\mathrm{Co3})_{\text {номо-1 }}$ \\
\hline & 36.00 & 3.00 \\
\hline & $\left(\mathrm{C}_{03}\right)_{\text {LUMo }}$ & $\left(\mathrm{C}_{03}\right)_{\text {LUMO+1 }}$ \\
\hline & 9.00 & 19.00 \\
\hline \multirow[t]{4}{*}{$\mathbf{O}_{4}$} & $(\mathrm{Co4})$ номо & $(\mathrm{Co4})$ номо-1 \\
\hline & 27.00 & 3.00 \\
\hline & $\left(\mathrm{C}_{03}\right)_{\text {LUmo }}$ & $\left(\mathrm{C}_{03}\right)_{\text {LUMO+1 }}$ \\
\hline & 27 & 3.00 \\
\hline
\end{tabular}


Table 2b. Coefficients $(\times 100)$ of molecular orbitals of iodinated pyruvic ester.

\begin{tabular}{|c|c|c|c|c|}
\hline \multirow{8}{*}{$\begin{array}{c}\text { Iodinated } \\
\text { pyruvic ester }\end{array}$} & $\left(\mathrm{C}_{\mathrm{C} 1}\right)_{\text {номо }}$ & $\left(\mathbf{C}_{\mathrm{C} 2}\right)$ номо & $\left(\mathrm{C}_{3}\right)_{\text {номо }}$ & $\left(\mathrm{C}_{\mathrm{I}}\right)_{\text {номо }}$ \\
\hline & 10.20 & 4.15 & 7.00 & 22.00 \\
\hline & $\left(\mathrm{C}_{\mathrm{C1}}\right)_{\text {номо+1 }}$ & $\left(\mathbf{C}_{\mathrm{C} 2}\right)_{\text {номо+1 }}$ & $\left(\mathrm{C}_{3}\right)_{\text {номо }+1}$ & $\left(\mathrm{C}_{\mathrm{I}}\right)_{\text {номо+1 }}$ \\
\hline & 8.60 & 1.10 & 4.40 & 9.00 \\
\hline & $\left(\mathrm{C}_{\mathrm{C} 1}\right)_{\text {LUMO }}$ & $\left(\mathrm{C}_{\mathrm{C} 2}\right)_{\text {LUMO }}$ & $\left(\mathrm{C}_{3}\right)_{\text {LUMO }}$ & $\left(\mathrm{C}_{\mathrm{I}}\right)_{\text {LUMO }}$ \\
\hline & 13.00 & 5.40 & 2.10 & 16.50 \\
\hline & $\left(\mathrm{C}_{\mathrm{C1}}\right)_{\text {LUMO+1 }}$ & $\left(\mathbf{C}_{\mathrm{C} 2}\right)_{\text {LUMO+1 }}$ & $\left(\mathrm{C}_{3}\right)_{\text {LUMO+1 }}$ & $\left(\mathrm{C}_{\mathrm{I}}\right)_{\text {LUMO+1 }}$ \\
\hline & 56.00 & 10.40 & 1.40 & 23.00 \\
\hline
\end{tabular}

This analysis showed that the coefficient of sulfur has a significant value in the molecular orbital HOMO and LUMO+1. At the same time, for the iodinated pyruvic ester, the contribution of the carbon $\mathrm{C}_{1}$ and the iodine atom $\mathrm{I}$ in the HOMO is more critical than that of the carbon $\mathrm{C}_{2}$ and $\mathrm{C}_{3}$. However, the values of the atomic coefficients of the reactive sites found experimentally ${ }^{8}$ are very close in the LUMO (case of the carbon $\mathrm{C}_{1}$ and the iodine atom). Nevertheless, the coefficients on the $\mathrm{C}_{2}$ and $\mathrm{C}_{3}$ carbons have negligible values; therefore, in the molecular orbital LUMO+1, the value of the atomic coefficient associated with $\mathrm{C}_{1}$ is much higher than that of the iodine atom as well as that of $\mathrm{C}_{2}$. The coefficient of $\mathrm{C}_{2}$ is not negligible at the level of the LUMO+1 but less critical than that of $\mathrm{C}_{1}$. Thus, the analysis of the atomic coefficients of the LUMO+1 (Table 1.b) of the iodinated pyruvic ester made it possible to detect the presence of three reactive centers which are: the carbon $\mathrm{C}_{1}$, the carbon $\mathrm{C}_{2}$ and the iodine atom. These results are in good agreement with the two hypotheses cited previously and proposed by the experimenters ${ }^{8}$.

The analysis of the data in Table 1 shows that the ion $\mathrm{HSO}_{3}^{-}$has a chemical potential more significant than that of the iodinated pyruvic ester, which indicates that the charge transfer or the electronic flow will be from hydrogen sulfite ion to the iodinated pyruvic ester. Therefore the ion $\mathrm{HSO}_{3}^{-}$will behave like a nucleophile and the pyruvic ester as an electrophile. Similarly, the analysis of the values of the global nucleophilic indices $\mathrm{N}$ shows that the hydrogen sulfite ion has a higher value of $3.31 \mathrm{eV}$ than that of the iodinated pyruvic ester which is $1.65 \mathrm{eV}$, hence the compound $\mathrm{HSO}_{3}^{-}$acts as an electron donor. The values of the global electrophilic indices $\omega$ indicate that the iodinated pyruvic ester is more electrophilic than the hydrogen sulfite. The calculated value of $\omega$ is $1.52 \mathrm{eV}$ for the iodinated pyruvic ester iodine ester and $0.05 \mathrm{eV}$ for hydrogen sulfite ion. Thus, the iodinated pyruvic ester would act as an acceptor of electrons. It can be noted that the proportion of maximum charge $\Delta \mathrm{N}_{\max }$ which can be acquired by a system from its environment is higher for the iodinated pyruvic ester. Also, the difference in electrophily $\Delta \omega$ between the hydrogen sulfite ion and the iodinated pyruvic ester is more significant than one, which indicates an appreciable polarity.

The values of the global indices, namely $\mathrm{N}$ and $\omega$, will be exploited after that for the calculation of local indices $\mathrm{N}_{\mathrm{k}}$ and $\omega_{\mathrm{k}}$ to locate the most favored attack sites.

\section{Local indices}

\section{Parr indices}

The use of Parr indices ${ }^{49,51-53}$. In the computation of local indices, namely the local electrophilic $\omega_{\mathrm{k}}$ and the local nucleophilic indices $\mathrm{N}_{\mathrm{k}}$ allows predicting the most prominent sites of attack leading to the products. The results of this study have been illustrated in Table 3. To deepen our analysis of reactive sites, a calculation of local electrophilic indices $\omega_{\mathrm{k}}$ and local nucleophilic indices $\mathrm{N}_{\mathrm{k}}$ has been performed on the molecular orbitals LUMO+1. In the case of the iodinated pyruvic ester, the values of local electrophilic and local nucleophilic indices $\omega_{\mathrm{k}}$, $\mathrm{N}_{\mathrm{k}}$ on the iodine atom are equal to $0.32 \mathrm{eV}$ and 0.07 $\mathrm{eV}$ respectively, while these indices are $0.27 \mathrm{eV}$ and $0.05 \mathrm{eV}$ on $\mathrm{C}_{1}$ but only $0.17 \mathrm{eV}$ and $0.03 \mathrm{eV}$ on-site $\mathrm{C}_{2}$. For the hydrogen sulfite ion, the values of the local nucleophilic indices of the oxygen atoms $\mathrm{O}_{2}$ and $\mathrm{O}_{3}$ are greater than the corresponding value of the sulfur atom, which is equal to $0.67 \mathrm{eV}$. This increase is due to the negative charge of the oxygen atom, which causes delocalization of the electrons leading thus to a sulfur attack. We conclude that the value of the electrophilic index of the iodine atom is the highest. Thus, the attack of the hydrogen sulfite ion will take place on the iodine atom, which confirms the preceding observations of NCI analysis of electron density ${ }^{16}$. 
Table 3. Parr indices $\mathrm{P}_{\mathrm{k}}^{+}$et $\mathrm{P}_{\mathrm{k}}^{-}$calculated with atomic spin density, $\omega_{\mathrm{k}}$ and $\mathrm{N}_{\mathrm{K}}$ in $\mathrm{eV}$.

\begin{tabular}{|c|c|c|c|c|}
\hline Site $(\mathrm{K})$ & $\mathbf{P}_{\mathbf{k}}^{+}$ & $P_{k}^{-}$ & $\omega_{k}$ & $N_{k}$ \\
\hline S & 0.630 & 0.203 & 0.0315 & 0.672 \\
\hline $\mathrm{O}_{2}$ & 0.084 & 0.333 & 0.0004 & 1.102 \\
\hline $\mathrm{O}_{3}$ & 0.080 & 0.319 & 0.0004 & 1.056 \\
\hline $\mathrm{O}_{4}$ & -0.013 & 0.163 & 0.0006 & 0.450 \\
\hline \multicolumn{5}{|c|}{ Iodinated pyruvic ester LUMO+1 } \\
\hline $\mathrm{C} 1$ & 0.175 & 0.028 & 0.266 & 0.046 \\
\hline $\mathrm{C} 2$ & 0.107 & -0.017 & 0.166 & -0.028 \\
\hline C3 & 0.031 & -0.013 & 0.047 & -0.021 \\
\hline I & 0.211 & 0.040 & 0.321 & 0.066 \\
\hline
\end{tabular}

\section{Conclusion}

The reduction reaction of the carbon-iodine bond of the iodinated pyruvic ester in aqueous solution leading to the formation of the non-halogenated pyruvic ester has been investigated on the DFT/B3LYP level. The sites of attack have been predicted using the reactivity indices calculated by natural population analysis. The analysis of the HOMO/LUMO energy gaps proves that the electron transfer takes place from the hydrogen sulfite ion considered as nucleophilic to the iodinated pyruvic ester considered as electrophilic. The calculation of Fukui and Parr indices indicates that the site of the attack by the hydrogen sulfite ion is on the iodine atom. This favors the second hypothesis quoted by the experimenters. These results are in conformity with the NCI analysis of the electron density in the approach of the hydrogen sulfite ion to the iodine atom. This reveals an attractive van der Waals interaction.

\section{References}

1- M. A. Molenda, S. Baś, O. El-Sepelgy, M. Stefaniak, J. Mlynarski: 'Chemistry of Pyruvate Enolates: anti-Selective Direct Aldol Reactions of Pyruvate Ester with Sugar Aldehydes Promoted by a Dinuclear Zinc Catalyst', Adv. Synth. Catal., 2015, 357 , 2098-2104.

2- Y. Pocker, J.E. Meany, C. Zadorojny, Reversible hydration of pyruvate esters. Thermodynamic and kinetic studies. J. Phys. Chem., 1971, 75, 792-799.

3- P. Coutrot, C. Grison, M. Tabyaoui, S. Czernecki, et J.-M. Valery, « Novel application of alkyl dihalogenoacetates; chain extension with an $\alpha$-ketoester unit of carbohydrates », J. Chem. Soc. Chem. Commun, 1988, 23, 1515-1516.

4- A. Lopalco, G. Dalwadi, S. Niu, R. L. Schowen, J. Douglas, V. J. Stella, Mechanism of Decarboxylation of Pyruvic Acid in the Presence of Hydrogen Peroxide, J. Pharm. Sci., 2016, 105, 705-713.
5- A.M. Ajami, C.A. Sims, M.P. Fink, Pyruvate ester composition and method of use for resuscitation after events of ischemia and reperfusion, 2005. US6846842B2.

6- S.M. Reddy, S.M., University Botany- III, (Plant Taxonomy, Plant Embryology, Plant Physiology. New Age International. 2007.

7- S. D. Varma, P. S. Devamanoharan, A. H. Ali: 'Prevention of Intracellular Oxidative Stress to Lens by Pyruvate and Its Ester', Free Radic. Res., 1998, 28, 131-135.

8- P. Coutrot, J. C. Combert, J. Villieras, Action des organomagnesiens sur les esters glycidiques $\alpha$-chlorés : préparations d'epoxycetones $\alpha$ chlorées. Tetrahedron Lett., 1971, 12, 1553-1556.

9- S. Jorio, H. Abou El Makarim, M. Tabyaoui: Formation of $\alpha$-Iodine Pyruvics Esters from $\alpha$ Chloroglycidic Esters Isomers in Diethyl Ether Solution: a DFT Study. 2018, 9, Issue 9, 2714-2722.

10- I. J. Borowitz, S. Firstenberg, G. B. Borowitz, D. Schuessler, Organophosphorus chemistry. XVII. Kinetics and mechanism of the Perkow reaction, J. Am. Chem. Soc., 1972, 94, 1623-1628.

11 - M. Sekine, K. Okimoto, K. Yamada, T. Hata, Silyl phosphites.15. Reactions of silyl phosphites with alpha. halo carbonyl compounds. Elucidation of the mechanism of the Perkow reaction and related reactions with confirmed experiments, J. Org. Chem., 1981, 46, 10, 2097-2107.

12- W. F. Barthel, B. H. Alexander, P. A. Giang, S. A. Hall, Insecticidal Phosphates Obtained by a New Rearrangement Reaction, J. Am. Chem. Soc., 1955, 77, 2424-2427.

13- A. D. Becke, K. E. Edgecombe, A simple measure of electron localization in atomic and molecular systems. J. Chem. Phys, 1990, 92, 5397.

14- B. Silvi, A. Savin, Classification of chemical bonds based on topological analysis of electron localization function. Nature, 1994, 371, 683-686. 
15- G. N. Lewis, The atom and the molecule, J. Am. Chem. Soc., 1916, 38, 762-785.

16- (a) S. Fiedler, J. Broecker, S. Keller, Protein folding in membranes, Cell. Mol. Life Sci. CMLS, 2010, 67, 1779-1798.

(b) K. A. Dill, Dominant forces in protein folding, Biochemistry, 1990, 29, 7133-7155.

17- M. A. Spackman, E. N. Maslen, Chemical properties from the promolecular, J. Phys. Chem., 1986, 90, 2020-2027.

18- A. M. Pendas, V. Luana, L. Pueyo, E. Francisco, P. Mori-Sanchez, Hirshfeld surfaces as approximations to interatomic surfaces, J. Chem. Phys., 2002, 117, 1017-1023.

19- J. A. Pople, P. M. W. Gill, B. G. Johnson, Kohn-Sham density-functional theory within a finite basis, Chem. Phys. Lett., 1992, 199, 557-560.

20- P.M.W. Gill, B.G. Johnson, J.A. Pople, A standard gird for density functional calculation, Chem. Phys. Lett., 1993, 209 (5-6), 506-512.

21- W. Yang, Direct calculation of electron density in density-functional theory, Phys. Rev. Lett., 1991, 66, 438-1441.

22- L. R. Domingo, M. J. Aurell, P. Pérez, R. Contreras: 'Quantitative Characterization of the Local Electrophilicity of Organic Molecules. Understanding the Regioselectivity on Diels-Alder Reactions', J. Phys. Chem., A, 2002, 106, 6871-6875.

23- R. G. Parr, R. A. Donnelly, M. Levy, W. E. Palke, Electronegativity: The density functional viewpoint, J. Chem. Phys., 1978, 68, 3801-3807.

24- R. G. Parr, R. G. Pearson, Absolute hardness: companion parameter to absolute electronegativity, J. Am. Chem. Soc., 1983, 105, 7512-7516.

25- R. G. Parr: in Horizons of Quantum Chemistry, eds. K. Fukui, B. Pullman, Springer Netherlands, 1980, 5-15.

26- L. R. Domingo, M. José Aurell, R. Jalal, M. Esseffar, A DFT study of the role of Lewis acid catalysts in the mechanism of the 1,3dipolar cycloaddition of nitrile imines towards electron-deficient acryloyl derivatives, Comput. Theor. Chem., 2012, 986, 6-13.

27- M. J. Frisch, G. W. Trucks, H. B. Schlegel, G. E. Scuseria, M. A. Robb, J. R. Cheeseman, G. Scalmani, V. Barone, B. Mennucci, G. A. Petersson and others: 'Gaussian 09, revision A. 2'.

28- Dennington R., Keith T., Milam J., Gauss View, Version 5, Semichem Inc., Shwnee Mission, KS, 2009.

29- D. Becke, Density-functional thermochemistry. III. The role of exact exchange, J. Chem. Phys., 1993, 98, 5648-5652.

30- R. Ditchfield, W. J. Hehre, J. A. Pople, SelfConsistent Molecular-Orbital Methods. IX. An Extended Gaussian-Type Basis for Molecular-
Orbital Studies of Organic Molecules, J. Chem. Phys., 1971, 54, 724-728.

31- W. J. Hehre, R. Ditchfield, J. A. Pople, SelfConsistent Molecular Orbital Methods. XII. Further Extensions of Gaussian-Type Basis Sets for Use in Molecular Orbital Studies of Organic Molecules, J. Chem. Phys., 1972, 56, 2257-2261.

32- P. C. Hariharan, J. A. Pople: 'Accuracy of AH $\mathrm{n}$ equilibrium geometries by single determinant molecular orbital theory', Mol. Phys., 1974, 27, 209-214.

33- M. S. Gordon M. S., The isomers of Silacyclopropane. Chem. Phys. Lett., 1980, 76, 163.

34- K.A. Peterson, D. Figgen, E. Goll, H. Stoll, M.J. Dolg, Systematically convergent basis sets with relativistic pseudopotentials. II. Smallcore pseudopotentials and correlation consistent basis sets for the post-d group 16-18 elements. Chem. Phys., 2003, 119, 11113.

35- M. Dolg, Valence correlation energies from pseudopotential calculations. Chem. Phys. Lett., 1996, 250, Issue 1, 75.-79.

36- H. Tatewaki, S. Huzinaga: 'A systematic preparation of new contracted Gaussian-type orbital sets. III. Second-row atoms from Li through ne', J. Comput. Chem., 1980, 1, 205-228.

37- Y. Sakai, H. Tatewaki, S. Huzinaga: 'A systematic preparation of new contracted Gaussian-type orbital sets. V. From Na through Ca', J. Comput. Chem., 1981, 2, 100-107.

38- Y. Sakai, H. Tatewaki, S. Huzinaga: 'A systematic preparation of new contracted Gaussian-type orbital sets. VIII. MINI-1 and MIDI-1 sets for Ga through Cd', J. Comput. Chem., 1982, 3, 6-13.

39- M. W. Wong, Vibrational frequency prediction using density functional theory, Chem. Phys. Lett., 1996, 256, 391-399.

40- J. B. Foresman, T. A. Keith, K. B. Wiberg, J. Snoonian, M. J. Frisch, Solvent Effects. 5. Influence of Cavity Shape, Truncation of Electrostatics, and Electron Correlation on ab Initio Reaction Field Calculations, J. Phys. Chem., 1996, 100, 16098-16104.

41- V. Barone, M. Cossi, J. Tomasi, A new definition of cavities for the computation of solvation free energies by the polarizable continuum model, J. Chem. Phys., 1997, 107, 3210-3221.

42- K. Marakchi, O. K. Kabbaj, N. Komiha, Etude DFT du mécanisme des réactions de cycloaddition dipolaire-1,3 de la C, Ndiphénylnitrone avec des dipolarophiles fluorés de type éthylénique et acétylénique, J. Fluor. Chem., 2002, 114, 81-89.

43- T. Lu, F. Chen, Multiwfn: A multifunctional wavefunction analyzer, J. Comput. Chem.,2012, 33, 580-592. 
44- J. R. Lane, J. Contreras-García, J.P. Piquemal, B. J. Miller, H. G. Kjaergaard, Are Bond Critical Points Really Critical for Hydrogen Bonding? J. Chem. Theory Comput., 2013, 9, 3263-3266.

45- E. R. Johnson, S. Keinan, P. Mori-Sánchez, J. Contreras-García, A. J. Cohen, W. Yang, Revealing Noncovalent Interactions, J. Am. Chem. Soc., 2010, 132, 6498-6506.

46- W. Humphrey, A. Dalke, K. Schulten. VMD: Visual molecular dynamics. Journal of Molecular Graphics, 1996, 14 (1), 33-38.

47- L. R. Domingo, M. T. Pisher, A DFT study of the Huisgen 1, 3-dipolar cycloaddition between hindered thiocarbonyl ylides and tetracyanoethylene, Tetrahedron, 2004, 60, 5053.

48- L. R. Domingo, M. Ríos-Gutiérrez, P. Pérez, Applications of the Conceptual Density Functional Theory Indices to Organic Chemistry Reactivity, Molecules, 2016, 21(6), 748.

49- L. R. Domingo, P. Pérez J. A. Sáez, Understanding the local reactivity in polar organic reactions through electrophilic and nucleophilic Parr functions, RSC Adv., 2013, 3, 1486-1494.
50- F. Fuster, A. Sevin B. Silvi, Topological Analysis of the Electron Localization Function (ELF) Applied to the Electrophilic Aromatic Substitution, J. Phys. Chem., A., 2000, 104, 852-858.

51- M. Salah, N. Komiha, O.K. Kabbaj, R. Ghailane, K. Marakchi, Computational study of the 1,3-dipolar cycloaddition between methyl 2-trifluorobutynoate and substituted azides in terms of reactivity indices and activation, Journal of molecular graphics and modelling, 2017, 73, 143-151.

52- A. Benallou, Z. Lakbaibi, H. Garmes, et H. E. A. El Abdallaoui, « The role of the polarity on the mechanism and selectivity in the $[3+2]$ cycloaddition reaction between $\mathrm{CF} 3$-ynone ylide and azide group: A quantum chemical investigation », J. Fluor. Chem., 2019, 219, 79-91.

53- A. Benallou, Z. Lakbaibi, H. E. A. El Abdallaoui, et H. Garmes, «Understanding the molecular mechanism in a regiospecific $[3+2]$ cycloaddition reaction including $\mathrm{CO}$ interaction: A MEDT study », RHAZES Green Appl. Chem., 2018, 3, 12, 01-12.

Supplementary: The numbering of atoms is imposed by the program package of Gaussian 09 .

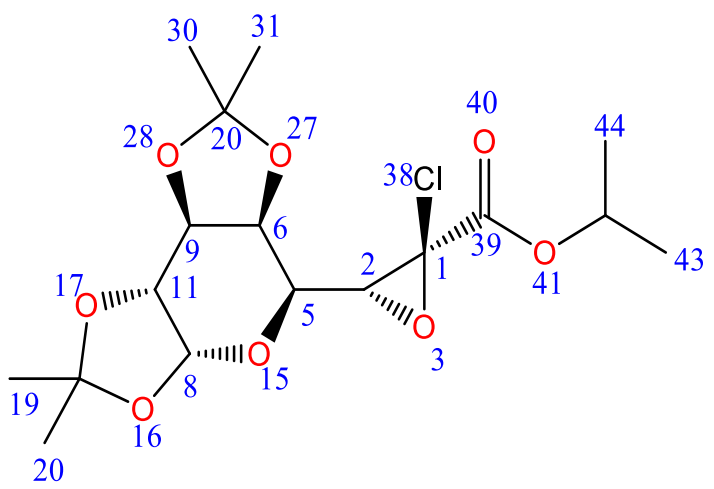

Figure 1S. Optimized structure of the $\alpha$-chloro glycidic ester.

Table 1S. Structural parameters of the $\alpha$-chloro glycidic ester.

\begin{tabular}{|cc|cc|cc|}
\hline \multicolumn{2}{|c|}{ Bond lengths $(\AA)$} & \multicolumn{2}{|c|}{ Bond angles $\left(^{\circ}\right)$} & \multicolumn{2}{c|}{ Dihedral angles $\left(^{\circ}\right)$} \\
\hline $\mathrm{C}_{1}-\mathrm{Cl}_{38}$ & 1.74 & $\mathrm{C}_{2}-\mathrm{C}_{1}-\mathrm{Cl}_{38}$ & 120.61 & $\mathrm{C}_{2}-\mathrm{C}_{5}-\mathrm{C}_{6}-\mathrm{C}_{9}$ & 157.77 \\
$\mathrm{C}_{1}-\mathrm{O}_{3}$ & 1.40 & $\mathrm{C}_{2}-\mathrm{C}_{5}-\mathrm{O}_{15}$ & 105.69 & $\mathrm{C}_{5}-\mathrm{C}_{2}-\mathrm{C}_{1}-\mathrm{C}_{39}$ & -153.14 \\
$\mathrm{C}_{2}-\mathrm{O}_{3}$ & 1.45 & $\mathrm{C}_{2}-\mathrm{C}_{1}-\mathrm{C}_{39}$ & 118.02 & $\mathrm{Cl}_{38}-\mathrm{C}_{1}-\mathrm{C}_{2}-\mathrm{C}_{5}$ & 0.0 \\
$\mathrm{C}_{1}-\mathrm{O}_{15}$ & 1.43 & $\mathrm{O}_{3}-\mathrm{C}_{2}-\mathrm{C}_{5}$ & 117.28 & $\mathrm{C}_{2}-\mathrm{C}_{1}-\mathrm{C}_{39}-\mathrm{O}_{41}$ & 139.95 \\
$\mathrm{C}_{6}-\mathrm{C}_{9}$ & 1.55 & $\mathrm{C}_{6}-\mathrm{C}_{5}-\mathrm{C}_{2}$ & 112.99 & $\mathrm{C}_{8}-\mathrm{O}_{15}-\mathrm{C}_{5}-\mathrm{C}_{2}$ & 168.56 \\
$\mathrm{C}_{1}-\mathrm{C}_{2}$ & 1.48 & $\mathrm{O}_{27}-\mathrm{C}_{6}-\mathrm{C}_{5}$ & 110.26 & $\mathrm{O}_{27}-\mathrm{C}_{6}-\mathrm{C}_{5}-\mathrm{C}_{2}$ & 41.22 \\
$\mathrm{C}_{1}-\mathrm{O}_{39}$ & 1.53 & $\mathrm{C}_{8}-\mathrm{O}_{5}-\mathrm{C}_{5}$ & 113.99 & $\mathrm{O}_{41}-\mathrm{C}_{39}-\mathrm{C}_{1}-\mathrm{Cll}_{38}$ & -13.69 \\
$\mathrm{C}_{8}-\mathrm{O}_{15}$ & 1.41 & $\mathrm{O}_{8}-\mathrm{C}_{9}-\mathrm{O}_{7}$ & 108.81 & $\mathrm{O}_{16}-\mathrm{C}_{8}-\mathrm{O}_{15}-\mathrm{C}_{5}$ & -78.27 \\
\hline
\end{tabular}




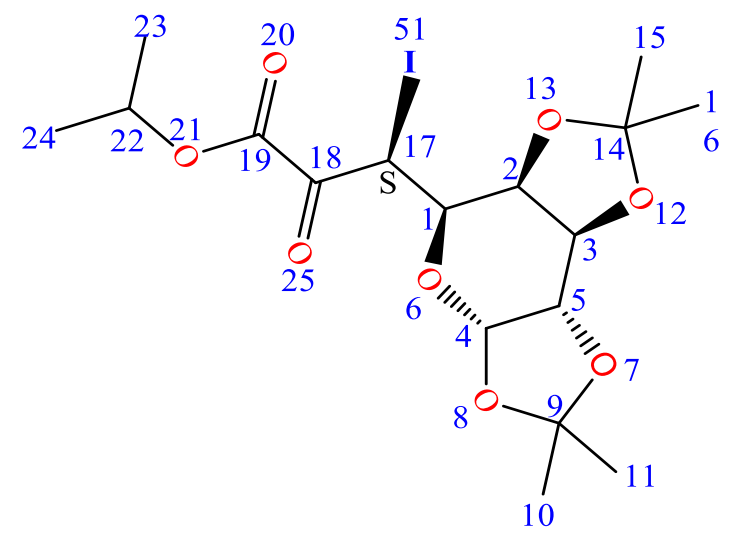

Figure 2S. Optimized structure of the iodinated pyruvic ester.

Table 2S. Structural parameters of the iodinated pyruvic ester in water solution.

\begin{tabular}{|cc|cc|cc|}
\hline \multicolumn{2}{|c|}{ Bond lengths $(\AA)$} & \multicolumn{2}{|c|}{ Bond angles $\left(^{\circ}\right)$} & \multicolumn{2}{|c|}{ Dihedral angles $\left(^{\circ}\right)$} \\
\hline $\mathrm{C}_{17}-\mathrm{I}$ & 2.25 & $\mathrm{I}^{\circ} \mathrm{C}_{17}-\mathrm{C}_{1}$ & 111.34 & $\mathrm{O}_{6}-\mathrm{C}_{1}-\mathrm{C}_{17}-\mathrm{I}$ & -62.67 \\
$\mathrm{C}_{18}-\mathrm{O}_{25}$ & 1.21 & $\mathrm{I}-\mathrm{C}_{17}-\mathrm{C}_{18}$ & 103.94 & $\mathrm{O}_{6}-\mathrm{C}_{1}-\mathrm{C}_{17}-\mathrm{C}_{18}$ & 179.65 \\
$\mathrm{C}_{17}-\mathrm{C}_{1}$ & 1.52 & $\mathrm{C}_{17}-\mathrm{C}_{18}-\mathrm{O}_{25}$ & 123.64 & $\mathrm{I}_{1} \mathrm{C}_{17}-\mathrm{C}_{1}-\mathrm{C}_{2}$ & 177.41 \\
$\mathrm{C}_{1}-\mathrm{O}_{6}$ & 1.43 & $\mathrm{C}_{17}-\mathrm{C}_{1}-\mathrm{O}_{6}$ & 107.16 & $\mathrm{C}_{2}-\mathrm{C}_{1}-\mathrm{C}_{17}-\mathrm{C}_{18}$ & 59.73 \\
$\mathrm{C}_{17}-\mathrm{C}_{18}$ & 1.51 & $\mathrm{O}_{6}-\mathrm{C}_{1}-\mathrm{C}_{2}$ & 109.43 & $\mathrm{O}_{7}-\mathrm{C}_{4}-\mathrm{O}_{6}-\mathrm{C}_{1}$ & -76.00 \\
$\mathrm{C}_{1}-\mathrm{C}_{2}$ & 1.54 & $\mathrm{O}_{6}-\mathrm{C}_{4}-\mathrm{C}_{5}$ & 111.40 & $\mathrm{O}_{13}-\mathrm{C}_{2}-\mathrm{C}_{1}-\mathrm{C}_{17}$ & 39.90 \\
$\mathrm{C}_{4}-\mathrm{O}_{6}$ & 1.41 & $\mathrm{C}_{3}-\mathrm{C}_{5}-\mathrm{O}_{8}$ & 108.72 & $\mathrm{O}_{25}-\mathrm{C}_{18}-\mathrm{C}_{17}-\mathrm{I}$ & -100.24 \\
$\mathrm{C}_{9}-\mathrm{O}_{8}$ & 1.43 & $\mathrm{O}_{8}-\mathrm{C}_{9}-\mathrm{O}_{7}$ & 104.89 & $\mathrm{O}_{21}-\mathrm{C}_{19}-\mathrm{C}_{18}-\mathrm{C}_{17}$ & -167.27 \\
\hline
\end{tabular}

Table 3S. Structural parameters of hydrogen sulfite in water solution.

\begin{tabular}{|cc|lr|cc|}
\hline \multicolumn{2}{|c|}{ Bond lengths $(\AA)$} & \multicolumn{2}{c|}{ Bond angles $\left(^{\circ}\right)$} & \multicolumn{2}{c|}{ Dihedral angles $\left(^{\circ}\right)$} \\
\hline $\mathrm{S}-\mathrm{O}_{2}$ & 1.513 & $\mathrm{O}_{2}-\mathrm{S}-\mathrm{O}_{3}$ & 111.58 & $\mathrm{O}_{2}-\mathrm{S}-\mathrm{O}_{4}-\mathrm{H}$ & -36.07 \\
$\mathrm{~S}-\mathrm{O}_{3}$ & 1.509 & $\mathrm{O}_{2}-\mathrm{S}-\mathrm{O}_{4}$ & 100.46 & $\mathrm{O}_{3}-\mathrm{S}-\mathrm{O}_{4}-\mathrm{H}$ & 79.26 \\
$\mathrm{~S}-\mathrm{O}_{4}$ & 1.750 & $\mathrm{O}_{2}-\mathrm{S}-\mathrm{O}_{4}$ & 103.32 & ----- & ----- \\
$\mathrm{O}_{4}-\mathrm{H}$ & 0.978 & $\mathrm{~S}_{2}-\mathrm{O}_{4}-\mathrm{H}$ & 103.80 & ----- & ----- \\
\hline
\end{tabular}

